\title{
Death Mechanisms of Pulmonary Alveolocytes in Mice Infected with Influenza Viruses A/H1N1/California/04/2009 and A/H5N1/Goose/Krasnoozerskoye/627/05 L. A. Cherdantseva ${ }^{1}$, A. V. Kovner', T. V. Sharkova ${ }^{2}$, V. A. Shkurupy ${ }^{1,3}$, A. M. Shestopalov ${ }^{1}$, and O. V. Potapova ${ }^{2}$
}

Translated from Byulleten'Eksperimental'noi Biologii i Meditsiny, Vol. 166, No. 11, pp. 583-586, November, 2018 Original article submitted July 27, 2018

\begin{abstract}
In CBA mice infected with influenza viruses A/H1N1/California/04/2009 and A/H5N1/Goose/ Krasnoozerskoye/627/05 in a dose of $10 \mathrm{MLD}_{50}$, the mechanisms of death of pulmonary alveolocytes over 10 postinfection days were studied by light microscopy, immunohistochemistry, and morphometry. In mice infected with $\mathrm{A} / \mathrm{H} 1 \mathrm{~N} 1$, alveolocytes died predominantly via necrosis, while apoptosis mostly employed the mitochondrial pathway. In mice infected with A/ H5N1, apoptosis was the dominant mechanism of alveolocyte death proceeded via membrane receptor signaling followed by switching to FAS-mediated pathway via activation of FADD, the apoptotic signal transduction protein.
\end{abstract}

Key Words: alveolocytes; influenza A viruses; apoptosis; necrosis; caspases 9, 3

All influenza A viruses are pneumotropic; they replicate in the pulmonary cells earlier than in other cells and exhibit pronounced cytodestructive effects $[6,8,10]$ implemented via apoptosis and necrosis. Both of them are triggered and realized by different mechanisms, which can be determined by virus machinery on the one hand, and the reaction to it by infected cells and regulatory systems of the body, on the other. However, these mechanisms are little studied, so the novel data are needed to refine pathogenesis of influenza viruses.

This work was designed to study prevalence, specificity of initiation, and implementation peculiarities of the alveolocytic death mechanisms in mice infected with influenza viruses A/H1N1/California/04/2009 (A/ $\mathrm{H} 1 \mathrm{~N} 1)$ and $\mathrm{A} / \mathrm{H} 5 \mathrm{~N} 1 / \mathrm{Goose} / \mathrm{Krasnoozerskoye/627/05}$ (A/H5N1).

${ }^{1}$ Research Institute of Experimental and Clinical Medicine, Federal Research Center of Fundamental and Translational Medicine, Novosibirsk; ${ }^{2}$ Optimum Medical Laboratory, Research-and-Educational Center, Sochi; ${ }^{3}$ Novosibirsk State Medical University, Novosibirsk, Russia. Address for correspondence: cherdanceff@yandex.ru L. A. Cherdantseva

\section{MATERIALS AND METHODS}

The experiments were carried out on 7-8-week-old CBA mice $(n=40)$ obtained from Breeding Center of Vector State Research Center of Virology and Biotechnology (Kol'tsovo, Novosibirsk region). All experimental procedures were carried out in accordance to European Convention for the Protection of Vertebrate Animals used for Experimental and Other Scientific Purposes (Strasbourg, 1986). The animals were sacrificed by cervical dislocation under ether narcosis.

The study employed influenza viruses $\mathrm{A} / \mathrm{H} 1 \mathrm{~N} 1 /$ California/04/2009 (A/H1N1) and A/H5N1/Goose/ Krasnoozerskoye/627/05 (A/H5N1), which had been isolated in Novosibirsk region. The mice were intranasally infected with equal viral doses of $10 \mathrm{MLD}_{50}$. The experiments with influenza viruses were carried out in strict adherence to the sanitary and epidemiological regulations SP 1.2.731 "Safety in Working with Microorganisms of Hazard Groups 3 and 4 and Helminths" (January 25, 2005).

The control groups $1(n=10)$ and $2(n=10)$ comprised the intact mice. The groups $3(n=10)$ and 4 
$(n=10)$ mice were infected with $\mathrm{A} / \mathrm{H} 5 \mathrm{~N} 1$ and $\mathrm{A} / \mathrm{H} 1 \mathrm{~N} 1$ viruses, respectively.

The lung specimens of groups 3 and 4 mice were obtained in $1,3,6$, and 10 days after infection. The controls were sacrificed in maintenance days 1 and 10 . Routine histological processing of the lung specimens included hematoxylin and eosin staining. Immunohistochemical methods [4] with specific primary antibodies were employed to detect the antigen of influenza A virus (InfA; Abcam) and expression of TNF $\alpha$ and TRAIL (DBS) as well as FAS and FADD (DBS) by the pulmonary cells. Expression of caspases 9 and 3 by alveolocytes was also assessed using Abcam assay kits.

Histological examination was performed under an AxioImager A1 microscope equipped with an AxioCam MRc camera (Carl Zeiss). Morphometry of pulmonary structural elements in the histological sections was carried out in a 100-point closed test system with the area of $3.64 \times 10^{5} \mu^{2}$ employing AxioVision (rel. 4.12) software.

The mean values of volume density ( $\mathrm{Vv})$ was calculated with Statistica software (StatSoft, Inc.). The data were analyzed statistically using Student's $t$ test at $p<0.05$. The results are presented as $m \pm S E M$.

\section{RESULTS}

In all periods of experiments, the lungs of mice infected with $\mathrm{A} / \mathrm{H} 5 \mathrm{~N} 1$ and $\mathrm{A} / \mathrm{H} 1 \mathrm{~N} 1$ viruses were characterized by the presence of cells in the states of necrosis and apoptosis, interstitial pneumonia with the forma- tion of inflammatory mononuclear-lymphocytic infiltrates, atelectasis foci, alveolar and interstitial edemam hyaline membranes in alveoli, massive hemorrhages, and thrombosis of blood vessels.

On days 1-6 after infection with $\mathrm{A} / \mathrm{H} 5 \mathrm{~N} 1$, the lungs exhibited a 6.5 -fold expansion of the foci with necrotically altered alveolocytes, but on day 10 , their volume density decreased by $20 \%$. In A/H1N1-infected mice, the volume density of pulmonary necrotic foci increased by 5.3 times during entire term of the study, and these foci were always larger than in $\mathrm{A} / \mathrm{H} 5 \mathrm{~N} 1$-infected mice (Table 1). In A/H5N1-infected mice, pulmonary foci with apoptotically altered alveolocytes were larger than the foci with necrotically modified cells (Table 1) throughout the observation period; the volume density of pulmonary necrotic foci was higher than that of foci with apoptotically altered alveolocytes (Table 1). However, the foci with inflammatory macrophage-lymphocyte infiltrates were larger in mice, whose alveolocytes were modified mostly by apoptosis than in mice with predominantly necrotic alveolocytes. The scale of the overall apoptotic and necrotic destructive processes was significantly greater in $\mathrm{A} / \mathrm{H} 5 \mathrm{~N} 1$-infected mice than in A/H1N1-infected ones. Hence, the necrotic processes in influenza are implemented via cytodestructive effects of the viruses; they are stimulated by hypoxia, ischemia, and thrombosis of the blood vessels resulting from enhanced tropicity of influenza viruses to endotheliocytes $[4,9]$. Seemingly, the apoptotic death of the cells is induced by hypoxia; its development depends on the number and activation degree of macrophages in

TABLE 1. Destructive Alterations and Inflammatory Processes in the Lungs of CBA Mice Infected with $\mathrm{A} / \mathrm{H} 1 \mathrm{~N} 1 /$ California/04/2009 and A/H5N1/Goose/Krasnoozerskoye/627/05 Influenza Viruses

\begin{tabular}{|c|c|c|c|c|c|}
\hline \multirow{2}{*}{ Parameter } & \multirow{2}{*}{$\begin{array}{l}\text { Postinfection } \\
\text { day }\end{array}$} & \multicolumn{4}{|c|}{ Group } \\
\hline & & intact & $\mathrm{A} / \mathrm{H} 5 \mathrm{~N} 1$ & intact & $\mathrm{A} / \mathrm{H} 1 \mathrm{~N} 1$ \\
\hline \multirow[t]{4}{*}{ Volume density of necrotic foci, \% } & 1 & $0.08 \pm 0.02$ & $1.48 \pm 0.54^{\star}$ & $0.26 \pm 0.08$ & $3.80 \pm 0.18^{\star 0}$ \\
\hline & 3 & & $5.76 \pm 0.76^{\star+}$ & & $9.08 \pm 0.16^{\star+o}$ \\
\hline & 6 & & $9.64 \pm 0.9^{\star+}$ & & $16.48 \pm 0.26^{\star+o}$ \\
\hline & 10 & & $7.70 \pm 1.26^{\star}$ & & $17.48 \pm 0.32 * \circ$ \\
\hline \multirow[t]{4}{*}{ Volume density of apoptotic foci, \% } & 1 & $0.18 \pm 0.06$ & $6.55 \pm 1.37^{*}$ & $0.08 \pm 0.02$ & $1.1 \pm 0.13^{\star 0}$ \\
\hline & 3 & & $30.96 \pm 1.91^{\star+}$ & & $2.1 \pm 0.10^{\star+o}$ \\
\hline & 6 & & $41.96 \pm 4.82^{\star+}$ & & $5.60 \pm 0.13^{\star+o}$ \\
\hline & 10 & & $21.10 \pm 4.14^{\star+}$ & & $5.80 \pm 0.12^{\star \circ}$ \\
\hline \multirow[t]{4}{*}{$\begin{array}{l}\text { Volume density of foci with } \\
\text { inflammatory infiltrates, \% }\end{array}$} & 1 & $0.12 \pm 0.08$ & $19.26 \pm 2.37^{\star}$ & $0.18 \pm 0.06$ & $2.70 \pm 0.16^{\star 0}$ \\
\hline & 3 & & $23.87 \pm 0.39^{\star}$ & & $6.98 \pm 0.16^{\star+o}$ \\
\hline & 6 & & $25.02 \pm 2.27^{\star+}$ & & $10.88 \pm 0.28^{\star+}$ \\
\hline & 10 & & $15.12 \pm 2.01^{\star+}$ & & $11.68 \pm 0.29^{\star+o}$ \\
\hline
\end{tabular}

Note. $p<0.05$ in comparison with *the corresponding intact group, ${ }^{+}$previous postinfection day, ${ }^{\circ} \mathrm{A} / \mathrm{H} 5 \mathrm{~N} 1$-infected mice. 


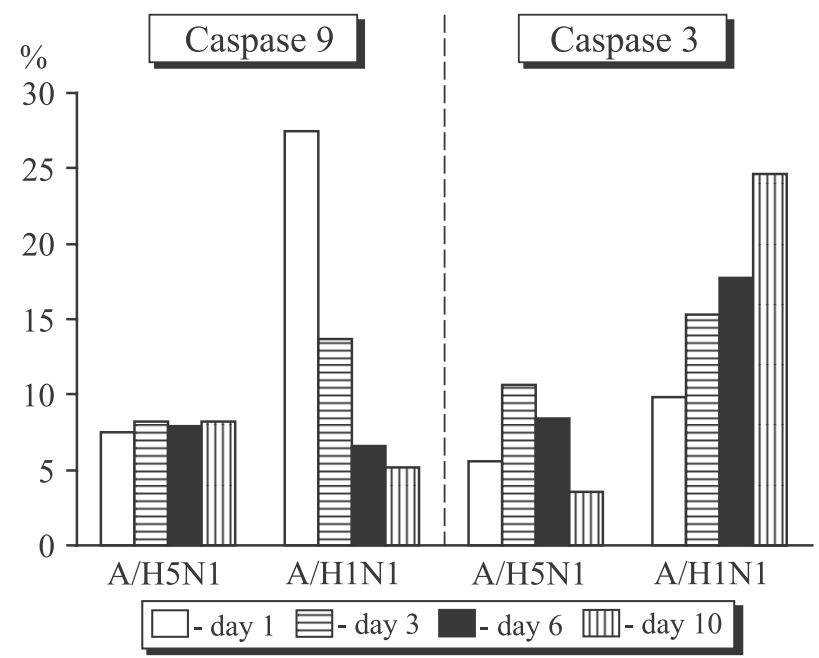

Fig. 1. Effects of $A / H 5 N 1$ and $A / H 1 N 1$ influenza viruses on the levels of caspase 9 and caspase 3 in mouse alveolocytes.

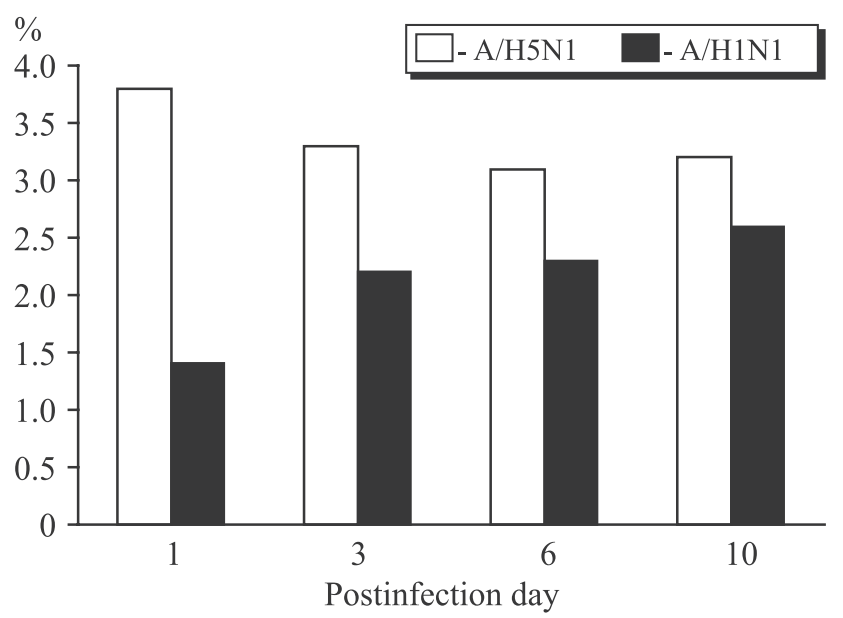

Fig. 2. Number of $T N F \alpha^{+}$alveolocytes in mice infected with $A / H 5 N 1$ and $\mathrm{A} / \mathrm{H} 1 \mathrm{~N} 1$ influenza viruses.

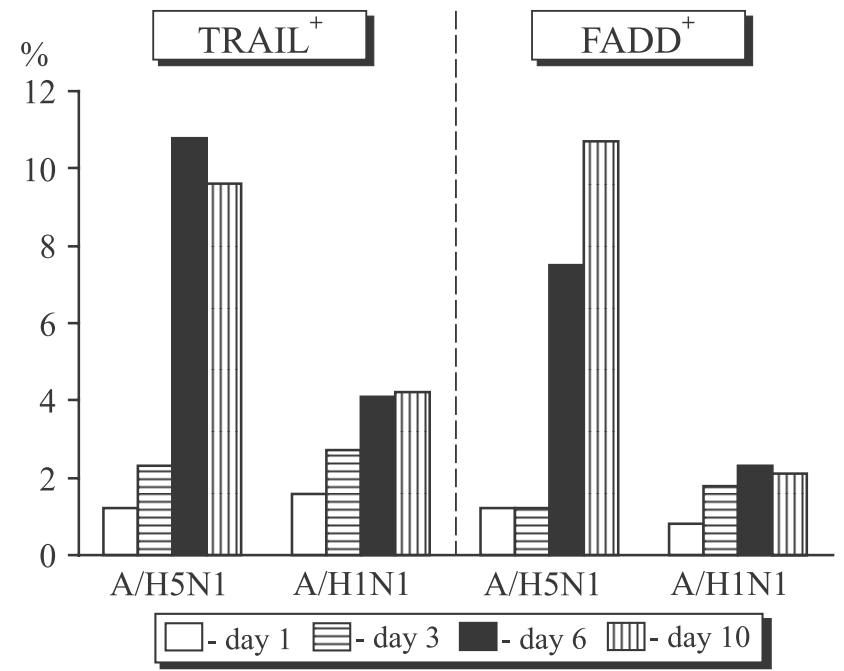

Fig. 3. Number of TRAIL+ and FADD ${ }^{+}$alveolocytes in mice infected with $\mathrm{A} / \mathrm{H} 5 \mathrm{~N} 1$ and $\mathrm{A} / \mathrm{H} 1 \mathrm{~N} 1$ influenza viruses. the infiltrates and their up-regulated secretion of nitric oxide, proteases $[1,2,4]$, and apoptosis-inducing factors, which is characteristic of mitochondrial pathway; moreover, apoptosis can be triggered from cell membrane via the plasmalemmal receptor pathway. Probably, the functional status and the number of activated macrophages can select the predominant pathways, which trigger apoptosis during viral influenzas. It is noteworthy that the scales of inflammatory infiltrates correlated with the total volume of the foci of destructive processes (necrosis and apoptosis), but not with that of the necrotic ones (Table 1).

In infected mice, immunohistochemistry visualized the positive staining of alveolocytes for viral antigen A [3-5].

On postinfection day 1 , numerous apoptotic alveolocytes expressing caspase 9 were detected in A/H1N1-infected mice. By postinfection day 10, the number of such cells decreased. In contrast, the number of the alveolocytes expressing caspase 3 changed in the reverse order, and it attained maximum to the end of experiments (Fig. 1). In A/H5N1-infected mice, the number of alveolocytes expressing caspase 9 was significantly smaller in all terms of experiments than in A/H1N1-infected mice on postinfection days 1 and 3 . Overall, the number of alveolocytes expressing caspase 3 was significantly higher in $\mathrm{A} / \mathrm{H} 1 \mathrm{~N} 1$-infected mice than in mice infected with A/H5N1 (Fig. 1). Expression of caspases 9 and 3 revealed in apoptotically modified alveolocytes at the early terms after infection with $\mathrm{A} /$ H1N1 virus indicated that the mitochondrial mechanism of apoptosis initiation takes place after infection with any type of influenza A viruses, although the viral determination of predominant initiation and implementation of apoptotic death probably exists as well.

Probability of realization of the plasmalemmal receptor mechanism of apoptosis in alveolocytes was assessed according to expression of TNF $\alpha$ and TRAIL markers (Figs. 2, 3). In $\mathrm{A} / \mathrm{H} 5 \mathrm{~N} 1$-infected mice, the number of apoptotically altered alveolocytes expressing TNF $\alpha$ was the greatest on postinfection day 1 , thereupon it decreased to postinfection days 6 and 10 (Fig. 2). In contrast, the number of such cells was smaller in the alveolocytes of A/H1N1-infected mice at all terms of experiments, although it gradually increased to postinfection day 10 (Fig. 2). It is important that in all terms of experiments, the size of foci of the macrophagal-lymphocytic infiltrates were larger in A/ H5N1-infected mice than in $\mathrm{A} / \mathrm{H} 1 \mathrm{~N} 1$-infected ones (Table 1). The number of apoptotically altered TRAIL ${ }^{+}$ and $\mathrm{FADD}^{+}$alveolocytes was the greatest on postinfection days 6 and 10 for both viruses, and the number of such alveolocytes was significantly higher in A/H5N1infected mice (Fig. 3). It is a common knowledge that under the effect of primary messengers, TNF $\alpha$ and 
TRAIL can form the ligand-receptor complexes thereby activating signal transduction to mitochondria and provoking energy imbalance in the mitochondria of infected cells, which results in damage to DNA and cell death in case of cytotoxic membrane lesions [7].

In addition, the lungs of mice infected with $\mathrm{A} /$ $\mathrm{H} 5 \mathrm{~N} 1$ and $\mathrm{A} / \mathrm{H} 1 \mathrm{~N} 1$ viruses contained the alveolocytes prone to apoptosis via activation of FADD, the apoptotic signal transduction protein. The number of alveolocytes expressing this apoptotic marker increased 9-fold during postinfection days $1-10$ in $\mathrm{A} / \mathrm{H} 5 \mathrm{~N} 1$-infected mice by contrast to 2.6 -fold increase observed in A/H1N1-infected mice (Fig. 3).

Despite similarities in pathomorphologic alterations in the lungs of CBA mice infected with $\mathrm{A} / \mathrm{H} 5 \mathrm{~N} 1$ and $\mathrm{A} / \mathrm{H} 1 \mathrm{~N} 1$ influenza viruses, the histologic examination revealed a larger scale of destructive apoptotic and necrotic alterations in $\mathrm{A} / \mathrm{H} 5 \mathrm{~N} 1$-infected mice. The immunohistochemical data showed that the leading mechanism of apoptosis in the lungs of A/H1N1-infected mice implicated the mitochondrial pathway of the cell death, although the plasmalemmal receptor pathway also contributed to apoptotic death. In contrast, in $\mathrm{A} / \mathrm{H} 5 \mathrm{~N} 1$-infected mice, the basic mechanism of alveolocytic apoptosis was FAS-mediated pathway realized via activation of FADD.

This work was performed with equipment of Common Use Center Modern Optical Systems, Research Institute of Experimental and Clinical Medicine. It was supported by the Russian Science Foundation (grant No. 18-54-7006).

\section{REFERENCES}

1. Domeniconi M, Hempstead BL, Chao MV. Pro-NGF secreted by astrocytes promotes motor neuron cell death. Mol. Cell. Neurosci. 2007;34(2):271-279.
2. Kacergius T, Ambrozaitis A, Deng Y, Gravenstein S. Neuraminidase inhibitors reduce nitric oxide production in influenza virus-infected and gamma interferon-activated RAW 264.7 macrophages. Pharmacol. Rep. 2006;58(6):924-930.

3. Kovner AV, Anikina AG, Potapova OV, Sharkova TV, Cherdanceva LA, Shkurupy VA, Shestopalov AM. Structural and functional changes in pulmonary macrophages and lungs of mice infected with influenza virus A/H5N1 A/goose/Krasnoozerskoye/627/05. Bull. Exp. Biol. Med. 2012;153(2):229232.

4. Kovner AV, Potapova OV, Shkurupy VA. Morphofunctional changes in the lung vascular endotheliocytes in mice with influenza A/H5N1 A/Goose/Krasnoozerskoye/627/05. Bull. Exp. Biol. Med. 2013;154(4):476-479.

5. Kovner AV, Potapova OV, Shkurupy VA, Shestopalov AM. Morphofunctional characteristics of pulmonary surfactant system and its effect on immune cells in influenza A (H1N1) pathogenesis. Open J. Pathol. 2016;6(1):1-7.

6. Kuiken T, Rimmelzwaan GF, Van Amerongen G, Osterhaus AD. Pathology of human influenza A (H5N1) virus infection in cynomolgus macaques (Macaca fascicularis). Vet. Pathol. 2003;40(3):304-310.

7. Lasso Pirot A, Fritz KI, Ashraf QM, Mishra OP, DelivoriaPapadopoulos M. Effects of severe hypocapnia on expression of Bax and Bcl-2 proteins, DNA fragmentation, and membrane peroxidation products in cerebral cortical mitochondria of newborn piglets. Neuropathology. 2007;91(1):20-27.

8. Sreta D, Kedkovid R, Tuamsang S, Kitikoon P, Thanawongnuwech R. Pathogenesis of swine influenza virus (Thai isolates) in weanling pigs: an experimental trial. Virol. J. 2009;6:34. doi: 10.1186/1743-422X-6-34.

9. Potapova OV, Kovner AV, Anikina AG, Cherdantseva LA, Sharkova TV, Shkurupy VA, Vasil'eva EV, Shestopalov AM. Studies of influenza A/H1N1 A/Tomsk/13/2010 virus topology during development of infectious process in mammals. Bull. Exp. Biol. Med. 2016;160(5. P. 683-686.

10. Xu T, Qiao J, Zhao L, Wang G, He G, Li K, Tian Y, Gao M, Wang J, Wang H, Dong C. Acute respiratory distress syndrome induced by avian influenza A (H5N1) virus in mice. Am. J. Respir. Crit. Care Med. 2006;174(9):1011-1017. 